Bangladesh J. Sci. Ind. Res. 42(1), 67-74, 2007

\title{
Studies on the Characterization, Lipids and Glyceride Compositions of Sesame (Sesamum indicum linn.) Seed Oil
}

\author{
M. S. Rahman M. A. Hossain, G. M. Ahmed and M. M. Uddin \\ BCSIR Laboratries, Binodpur Bazar, Rajshahi-6206, Bangladesh
}

\begin{abstract}
The oil of 3 different sesame (Sesamum indicum linn.) varieties were extracted. The physico-chemical characteristics, lipids and glyceride compositions of oil were studied. The oil content of sesame seed kernels grown under the soil and climatic condition of Bangladesh varied from 42.5-46.2 \% depending on the variety. The total lipid extracts were fractionated into three major lipid groups neutral lipids, glycolipids and phospholipids by silicic acid column chromatography. The neutral lipids were averaged to $92.5 \%$ of the total weight of the lipid applied. The oils were fractionated into mono-, di-and triglycerides by silicic acid columb chromatography. The triglycerides varied from 90.3-92.5 \%, diglycerides from 2.5-3.2 \% and monoglycerides from 2.4-3.1 \% depending on the varieties and soil conditions of the areas on which the plant grow. Saturated and unsaturated fatty acids present in the oil were separated and varied from 12.2-15.4 \% and 82.9-85.8 \% respectively. The pecentage composition of fatty acids was found to be linoleic acid 40.3, oleic acid 44.0, stearic acid 4.3, palmitic acid 9.0 and arachidic acid 0.7.
\end{abstract}

\section{Introduction}

The oil seed is an important group of crops extensively grown in Bangladesh. The conventional oil seeds mainiy cultivated in Bangladesh are Mustard, Rape seed, Sesame and Soyabean among which Sesame is considered as one of the important oil seed crops in Bangladesh. It is the second major oil seed crop in Bangladesh both in respect of acreage and production (B.B.S. 1991). As an annual crop it is cultivated widely almost in all the districts of Bangladesh because the soil texture and climatic condition of Bangladesh are quite suitable for its cultivation. The commonly cultivated varieties in the country are black and white seeded. In some districts, the brown seeded varieties are grown to some extent. Most of the sesame seeds are used for oil extraction and the rest are used for planting and edible purposes. 
Like other developing countries, Bangladesh is facing acute shortage of edible and inedible industrial oils. So, she is compelled to import the oils from abroad in lieu of many valuable foreign currencies. Under the above cirecumstances sesame oil can play a vital role in bridging the vegetable oil gap in the country. The oil is consumed largely as a cooking and salad oil (Swern et.al., 1964). As regards to its properties the oil resembles olive oil (Watt, 1972). The oil is also used for the manufacture of oleo-margarine soaps and cosmetics (Rose, 1966). The seed is used as nourishing and as flavouring agent (1988).

The results of a recent study indicated that sesame oil may help to reduce high blood pressure and lower the amount of medication needed to control hypertension (Shultz, 2003).

The composition of oil varies with the source (Lakshminarayana, 1977) and depends on factors such as climatic conditions, soil type, maturity of plant and variety (Sallans 1964; Fick, 1973). The physicochemical properties of oils are directly related to their lipids and glyceride composition. So, knowledge on the compositional factors is very essential in connection with the properties. The present work had, therefore, been undertaken with a view to carry on a complete chemical investigation of the oil as regards to its characterization, lipids and glyceriede compositions.

\section{Materials and Methods}

Ripe and matured sesame seeds were collected from the local market. The seeds were deshelled manually and the kernels thus obtained were crushed into smaller particles in a glass mortar and dried in the oven at a temperature of $105^{\circ} \mathrm{C}$ to about $4.6 \%$ moisture. The misture content in the fresh kernel was determined by IUPAC methods (1979). The oil was then extracted with n-Hexane in a Soxhlet apparatus for 8 hours. n-Hexane as extracted solvent has been selected because this solvent has better effect over other polar solvents like alcohol, ketone, aldehyde, ethers, ester etc (Horn et.al., 1982). The solvent was removed by using a rotary vacuum evaporator and the percentage of oil content was calculated. The crude oil thus obtained was purified in a colum (Neutral alumina in pet. ether) using pet ether: ether (70-30) as the eluting solvent. The purity of the oil was checked by normal TLC. The specified gravity of the oil was calculated at $28^{\circ} \mathrm{C}$ by standard IUPAC methods. Moisture and volatile matter in the oil were also determined by IUPAC method. The free fatty acid (FFA), saponification vlaue, peroxide value and unsaponificable matters in the oil were determined by the standard AOCS methods (1980). Hanus method was followed to determine the iodine value of the oil (AOAC, 1955). 


\section{Separation of glycerides}

The whole oil was separated into mono-, diand triglycerides on silicic acid (E. Merck, Darmstadt, Germany, 70-230 mesh) column. The silicic acid was activated at $120^{\circ} \mathrm{C}$ overnight and again for 1 hour immediately before the column was perpared. Then the silicic acid was hydrated with $5 \%$ (w/w) water. A slurry of $25 \mathrm{~g}$ of silicic acid in chloroform was poured into the columb (2.2 $\mathrm{cm}$ i.d). One gm oil was dissolved in $15 \mathrm{ml}$ of chloroform and quantitatively transferred to the column. The triglyceride was eluted with $200 \mathrm{ml}$ of benzene, diglyceride with $200 \mathrm{ml}$ of a $1: 9 \mathrm{v} / \mathrm{v}$ mixture of diethyl ether and benzene and monoglyceride with $200 \mathrm{ml}$ of diethyl ether (Gafur et.al., 1993). The elution was controlled at a flow rate of $1.5-2 \mathrm{ml} / \mathrm{min}$.

The elution of each fraction was monitored by micro slide thin layer chromatography (TLC) to ensure uniformity of separation of each class of glyceride during silicic acid chromatography and the eluted solvents were collected in weighed flasks. The purity of glyceride classed was further checked by TLC using silica gel developed with n-hexane : diethyl ether 80/20 (v/v) and visualization with chromic-sulphuric acid at $180^{\circ} \mathrm{C}$. The glyceride classes were identifies by comparison of $\mathrm{R}_{\mathrm{f}}$ values with standard references. The weight percentage of each glyceride class was based on total glyceride recovered which averaged 98.6 of the total glyceride applied.

\section{Fractionation of Sesame seed lipid by column chromatography}

Three major lipid classed of crude oil were fractionated by silicic acid (E. Merck, Darmastad, Germany, 70-230 mesh) column chromatography (Rouser and Kritchevshy, 1967). The silicic acid was washed with water and methanol to remove fines and impurities. It was activated at $120^{\circ} \mathrm{C}$ overnight and again for 1 hour immediately before the column was prepared. A slurry of $25 \mathrm{~g}$ of silicic acid in chloroform was poured in to the column $(2.2 \mathrm{~cm} \mathrm{i.} \mathrm{d),} \mathrm{150mg} \mathrm{of} \mathrm{total}$ lipids were dissolved in $5 \mathrm{ml}$ eluting solvent and quantitatively transferred to the column. Neutral lipids were eluted with $200 \mathrm{ml}$ of methanol. The elution was controlled at a flow rate of $0.5 \mathrm{ml}-1.0 \mathrm{ml} / \mathrm{min}$. The complete elution of each fraction was monitored by micro slide TLC during silicic acid column chromatography and the eluted solvents were collected in a weighed flask. The fractions thus obtained were evaporated in a rotary vacuum evaporator and dried under reduced pressure before being weighed. The percentages of these fractions were determined by gravimetric method.

\section{Separation of saturated and unsaturated fatty acids present in the seed oil}

Separation of saturated and unsaturated fatty acids was carried out by Lead-Salt ether method (Das, 1989) on about 50gm of oil. The oil was saponified with alcoholic caustic soda to obtain soap solution. An excess of 
lead acetate solution was added to the soap solution to form a mixture of lead salts of fatty acids which were then separated by filtration. Diethyl ether was added to the mixture of lead salts and the whole mixture was boiled for 15 minutes and then cooled at $0^{\circ} \mathrm{C}$ for 24 hours. The precipitated lead salts of saturated fatty acids so formed were separated from the solution of lead salts of unsaturated fatty acids by filtration. The lead salts of unsaturated fatty acids were obtained by removing the ether from the ethereal solution. Each group of lead salts was suspended in water and treated with sufficient hydrochloric acid (35\%) to form fatty acids and lead chlorides. The mixture was then extracted with ether to obtain the ethereal solution of each group. On evaporating the ether the fatty acids were obtained in separate groups. Finally masses of saturated and unsaturated fatty acids were obtained by weighing them separately.

\section{Fatty acid composition of sesame seed oil}

Fatty acid compositions present in the Sesame seed oil was analyzed as its methyl ester, which was prepared by the boron trifiuoride methanol method (Morrison and Smith, 1964). A GCD pye Unicam chromatograph equipped with a flame ionization detector (FID) was used to determine the fatty acid methyl ester. Nitrogen carrier gas was used at a flow rate of $30 \mathrm{ml} / \mathrm{min}$. Fatty acids were separated on a $1.8 \mathrm{~m}$ x $2 \mathrm{~mm}$ i.d. glass column packed with $6 \%$ BDS
(Butanediol Succinate Polyesters) on solid support Anakrom ABS 100/120 mesh. Analysis was carried out at isothermal column temperature of $190^{\circ} \mathrm{C}$, injector and detector temperature for all GLC analysis were $230^{\circ} \mathrm{C}$. The peaks were identified by comparison with standard methyl esters for retention times, by ploting the log of retention time against equivalent carbon length (ECL). The peak areas were determined by multiplying peak height by width at half height. The percentage of each peak was calculated as the percentage of the area of all the peaks.

\section{Results and Discussion}

Sesame seed kernels from three different varieties had been studied to evaluate yhe physico-chemical characteristics, lipids and glyceride compositions. The physico-chemical characteristics of the extracted oils were determined by the conventional methods and the results were shown in Table I. The results (Table I) indicated that the oil from the white variety differed from those of the other two in having a higher refractive index (1.4694), iodine value (118.0) and unsaponifiable matter (1.8 \%) and a lower saponification value (182.0). These results of the oil more or less agree with the reported results (Andros el.al., 1950). Specific gravity sand refractive index of the other two varieties were comparable with those of important vegetable oils (Hilditch, 1949). 
Table I. Physico-chemical characteristics of sesame seed oil

\begin{tabular}{c|l|c|c|c}
\hline SI. & \multirow{2}{*}{ No. } & \multicolumn{3}{|c}{ Name of the varieties } \\
\cline { 3 - 5 } Nysical-Chemical Characteristics & Black & Brown & White \\
\hline 1. & Percentage of oil & $42.5 \pm 0.289$ & $44.3 \pm 0.153$ & $46.2 \pm 0.153$ \\
2. & Moisture and volatile matter (\%) & $5.3 \pm 0.057$ & $5.5 \pm 0.057$ & $5.2 \pm 0.115$ \\
3. & Specific gravity at $28^{\mathrm{O}} \mathrm{C}$ & $0.915 \pm 0.001$ & $0.913 \pm 0.001$ & $0.917 \pm 0.001$ \\
4. & Refractive index at $28^{\mathrm{O}} \mathrm{C}$ & $1.4565 \pm 0.00005$ & $1.4560 \pm 0.00001$ & $1.4694 \pm 0.00005$ \\
5. & Free fatty acid as oleic (\%) & $2.0 \pm 0.115$ & $1.8 \pm 0.115$ & $1.5 \pm 0.173$ \\
6. & Iodine value & $110 \pm 1.555$ & $112 \pm 1.555$ & $118 \pm 1.527$ \\
7. & Saponification value & $190 \pm 1.527$ & $192 \pm 1.527$ & $182 \pm 1.154$ \\
8. & Unsaponificable matter (\%) & $1.6 \pm 0.115$ & $1.4 \pm 0.100$ & $1.8 \pm 0.115$ \\
9. & Melting point ( $\left.{ }^{\mathrm{O}} \mathrm{C}\right)$ & $30-31^{\mathrm{O}} \mathrm{C} \pm 0.00$ & $30-31^{\mathrm{O}} \mathrm{C} \pm 0.00$ & $30-31^{\mathrm{O}} \mathrm{C} \pm 0.00$ \\
10. & Peroxide vlaue (m. eqv. kg) & $1.20 \pm 0.011$ & $1.25 \pm 0.011$ & $1.23 \pm 0.011$ \\
\hline
\end{tabular}

Mean value of three experimental results

Table II. Glyceride composition of sesame seed oil (weight \%)

\begin{tabular}{c|c|c|c|c}
\hline Name of the varieties & Monoglyceride & Diglyceride & Triglyceride & FFA \\
\hline Black & $2.4 \pm 0.057$ & $2.8 \pm 0.173$ & $91.8 \pm 0.057$ & $1.8 \pm 0.115$ \\
Brown & $3.1 \pm 0.173$ & $3.2 \pm 0.057$ & $90.3 \pm 0.057$ & $1.6 \pm 0.115$ \\
White & $2.9 \pm 0.057$ & $2.5 \pm 0.057$ & $92.3 \pm 0.057$ & $1.2 \pm 0.115$ \\
\hline
\end{tabular}

Mean value of three experimental results

The whole oil was fractionated into mono-, di-, and triglycerides by means of column chromatogaphy and the results were presented in Table II. From the results in Table II, it was evident that mono- and diglycerides in the Brown variety were found to be higher and triglycerides were lower in comparison with other two varieties. The highest triglyceride was found in the variety white $(92.3 \%)$. The results revealed that triglycerides in all the three samples irrespective of origin accounted for over $90 \%$ of the total weight of the oil.
Total extracted sesame seed lipids were separated into neutral lipids, glycolipids and phospholipids by silicic acid column and the results were depicted in Table III. The results

Table III. Lipid composition of sesame seed oil (weight \%)

\begin{tabular}{c|c|c|c}
\hline $\begin{array}{c}\text { Name of } \\
\text { the varieties }\end{array}$ & $\begin{array}{c}\text { Neutral } \\
\text { lipid }\end{array}$ & Glycolipid & Phospholipid \\
\hline Black & $92.5 \pm 0.251$ & $5.8 \pm 0.115$ & $0.095 \pm 0.001$ \\
Brown & $91.7 \pm 0.115$ & $5.7 \pm 0.057$ & $0.082 \pm 0.0005$ \\
White & $93.3 \pm 0.264$ & $5.6 \pm 0.115$ & $0.085 \pm 0.001$ \\
\hline
\end{tabular}

Mean value of three experimental results 
(Table III) indicated that no significant change in the lipid composition among the three sample was noticed. But it was remarkable to note that the percentages of phospholipids (Table III) were found to be very lower (0.082-0.090 \%) in comparison with other vegetable oils (Gafur, et.al. 1993; Sayeed, et.al. 1999; Ali, et.al., 1995). From the results shown in Table III, it was observed that the neutral lipids were averaged to $92.5 \%$ of the total weight of the lipid applied.

The saturated and unsaturated fatty acids present in the oil were separated by Lead-Salt ether method and the results were shown in Table IV. From the results, it was observed that the percentage of saturated and

Table IV. Percentage of saturated and unsaturated fatty acids

\begin{tabular}{c|c|c}
\hline $\begin{array}{c}\text { Name of } \\
\text { the varieties }\end{array}$ & $\begin{array}{c}\text { Saturated fatty } \\
\text { acids }\end{array}$ & $\begin{array}{c}\text { Unsaturated } \\
\text { fatty acids }\end{array}$ \\
\hline Black & 15.4 & 83.2 \\
Brown & 14.3 & 82.9 \\
White & 12.2 & 85.8 \\
\hline
\end{tabular}

Mean value of three experimental results

unsaturated fatty acids present in the oil of Black and Brown varieties were almost similar. But a slight variation of the percentage of fatty acid composition of the oil in the variety of white was noticed than those of other two. So the higher percentages of unsaturated fatty acids in the white variety proves it to be slightly better than those of other two varieties.
To know the nature of the fatty acid composition present in the sesame seed oil, one of the popular varieties i.e. Black variety was analysed by GLC and the results were shown in Table V. Gas chromatographic analysis showed that unsaturated fatty acids present in sesame seed oil were mainly linoleic (44.0\%) and oleic (40.3\%), which altogether accounted for over $84 \%$ of the total fatty acids.

Table V. The fatty acid composition of sesame seed oil of black variety (weight \%)

\begin{tabular}{c|c}
\hline Fatty acids & Weight percent \\
\hline $\mathrm{C}_{16: 0}$ & 9.0 \\
$\mathrm{C}_{18: 0}$ & 4.3 \\
$\mathrm{C}_{18: 1}$ & 44.0 \\
$\mathrm{C}_{18: 2}$ & 40.3 \\
$\mathrm{C}_{20: 0}$ & 0.7 \\
\hline
\end{tabular}

\section{Conclusion}

Sesame is considered as one of the important oil seed crops in Bangladesh. It contains 42.5-46.2 \% edible oil, which is of high quality and can be used as a salad oil with little or no winterizing. From the experiment it has been found that the oil contains very lower percentages of phospholipids and higher percentages of triglycerides and unsaturated fatty acids which make the oil more suitable for using it as cooking purposes. Again, the oil may be considered as a potential source of unsaturated fatty acids. From the above findings, the oil extracted from white variety has been found slightly 
better than those of other two varieties in respect to its higher oil percentage triglycerides, unsaturated fatty acids lower percentage of free fatty acid.

\section{Reference}

Ali, M.H. Rahman, M.S. Ahmed, G.M. Hossain, M.A. Uddin M.M. and Gofur, M.A. (1995) Studes on the effect of moisture during storage on major ground nut seed constituents : oil, protein, fatty acids and lipid compositions. Bangladesh J. Sci. Ind. Res., 30(1) : 93-104.

Andros et.al., (1950) J. Amer. Oil Chem. Soc., $27: 31$.

Association of Official Agricultural Chemicsts; Official Methods of Analysis, Washington, 8th Ed. (1955) 468.

Bangladesh Bureau of Statistics (B.B.S.) Govt. of the People Republic of Bangladesh (1991) 195.

Das, R.K. (1989) Industrial Chemistry, Part-2; Kalyani Publishers, New Delhi, India, 279.

Fick, G.N. (1973) JAOCS, 50 : 529.

Gafur, M.A. Rahman, M.S. Ahmed, G.M. Hossain, A. and Haque, M.E. (1993) Studies on the characterization and glyceride composition of Tobacco (Nicotina tobacum) seed oil. Bangladesh J. Sci. Ind. Res. 27(3) : 25-31.
Gafur, M.A. Rahman, M.S. and Ahmed, G.M. (1993) Studies on the selection of suitable solvent mixture for the extraction of mango seed lipids. Bangladesh J. Sci. Ind. Res. 28(4) : 100-109.

Hilditch, T.P. (1949) The Industrial Chemistry of the Fats and Waxes 3rd Ed. Bailliere Tindall and Cox, London, pp. 80.

Horn, R.J. Koltun, S. and Graci, A. V. (1982) Jr. JAOCS, $59: 674$.

International Union of Pure and Applied Chemistry, Standard Methods for the Analysis of Oils, Fats and Derivatives, Pargamon Press, 6th Ed. (1979) pp. 126.

Lakshminarayana, G.L. (1977) Oil Technol. Assoc. India 10 : 75.

Morrison, W.R. and Smith, L.M. (1964) J. Lipid Res. $5: 600$.

Mowlah, G. Sheik, N.M. and Kamal, A.S.M. (1990) A Hand book on Edible Oils and Fats, 1st Ed., pp. 323.

Official and Tentative Methods of the American Oil Chemists' Society, I and II, 3rd Ed. (1980).

Rose, E. (1966) The Chemical Condensed Dictionary, 7th Ed. pp 840.

Rouser, G. and Kritchevsky, G. (1967) Lipid Chromatographic analysis, Vol. I : 99-112. 
Sallans, H.R. (1964) JAOCS, 41 : 215.

Sayeed, M.A. Ali, M.A. Astaq Mohal Khan, G.R.M. and Rahman, M.S. (1999) Studies on the characterization and glyceride composition of cassia fistula seed oil. Bangladesh J. Sci. Ind Res. 34 (1) : 144-148.

Shultz T.M. (2003) Proceding of the InterAmerican Society of Hypertension, Published in Free Weekly New flash, (June 7).

Swern, D. Mattil, K.F. Norris, F.A. and Stirton, A. J. (1964) Bailey's Industrial Oil and Fat Products, 3rd Ed. pp. 208.
The Wealth of India, A dictionary of Indian Raw Materials and Industrial Products, Vol. IX (1988) pp. 289.

Watt, G. (1972) A Dictionary of the Economic Products of India, Vol. VI, part II, 2nd Ed. 506.

Received : March 19, 2006;

Accepted : March 14, 2007 